\title{
Toll Collection System
}

\author{
Shraddha Haveli ${ }^{1}$, Vaishnavi Ingle ${ }^{2}$, Pranjal Parge ${ }^{3}$, Nutan Bhujbal ${ }^{4}$, Ms. N.S. Meher ${ }^{5}$ \\ Student, Information Technology, Pimpri Chinchwad Polytechnic, Pune, India ${ }^{1,2,3,4}$ \\ Lecturer, Information Technology, Pimpri Chinchwad Polytechnic, Pune, India ${ }^{5}$
}

\begin{abstract}
Developing countries like India need a significant improvement in infrastructure such as Roads or Highways. These highway constructions are very costly; therefore tolls are collected by citizens. Normally Public private partnerships are made to construct such a huge projects. The money spent on these projects can be regained by collecting toll from the passengers who use the roads. In India toll collection system has problem like escaping toll booths, long queues now only 100 vehicles per hour can pass through toll plaza, if more vehicles arrive it may occur traffic jams. To solve this we are developing geo-fences using GPS. By comparing the position of the vehicle and toll plaza, the owner of the vehicle can be charged from the account.
\end{abstract}

Keywords: Automated, QR-Code, GPS, Account

\section{INTRODUCTION}

If you're going or travelling a long distance we will have to stop and pay some money at toll booth called as toll. This toll is taken for the use of further road but as India is developing country and numbers of vehicles are increasing day by day. The toll lines are creating traffic at toll booth which doesn't follow time management for them. The collection of toll done manually by a person called toll collector. So this takes a much time to avoid the time consumption and pollution, fuel consumption we are introducing QR Code based toll collection system. QR Code is short for Quick Response Code. It is best and easy way of storing information of user as well as vehicle. So user data consist of owner name, phone number, address, and other related information of owner. Vehicle data consist vehicle number, vehicle type, user type like pass holder or non-pass holder, etc. By scanning these QR Code toll amount will automatically deduct from your bank account and if any vehicle is found stolen the it will automatically Compare to stolen vehicle database and will alert the nearby police station. It will save time and help to find stolen vehicle.

\section{EXISTING SYSTEM}

Owner of vehicle stop and pay a toll to the toll collector present in a tollbooth. The amount which is to be paid by the owner of the vehicle is decided by Toll Collector. After the toll was paid then only gates were raised. Cash, credit/debit cards can be accepted by Toll Collector.

\section{PROPOSED SYSTEM}

Proposed system contains combination of toll collection and vehicle identification system. User register on system, after registration QR code get generated. QR code carries all the details about vehicle and its owner. At tollbooth, toll collector will scan QR code and determine owner and vehicle. Also he will check owner is pass holder or non-pass holder. If owner is regular owner then deduct amount according to one way/two way travelling toll charges. Whenever, a pass is renewed, will generate new QR code. If owner is Pass holder he will be allowed to move forward and if owner is regular owner the respective charges will deduct after scanning of QR code. At the same time we identify vehicle is stolen vehicle or not.

\section{SYSTEM ARCHITECTURE}

\footnotetext{
$>\quad$ User:

- $\quad$ Vehicle owner/User have to register to the system with all his/her personal information (Owner name, email id, contact number, address etc.) and also information related to the vehicle.(vehicle number, vehicle type, vehicle model etc.)

- User renews his/her monthly pass.

$>\quad$ Toll Collector:

- When User will go at toll booth area, then toll collector scan the QR Code of that user.

- $\quad$ System will collect toll after scanning QR-Code.

$>\quad$ System:

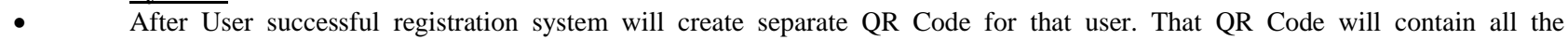
information related to the user and his/her vehicle.

- System verifies vehicle is stolen or not.
} 
Vol. 8, Issue 1, January 2019

- If vehicle is stolen then system will alert nearby to police station.

- $\quad$ Toll amount is determined after scanning QR-Code.

- $\quad$ Toll amount deducted from user account.

- $\quad$ System regenerate QR-Code after renewing monthly pass

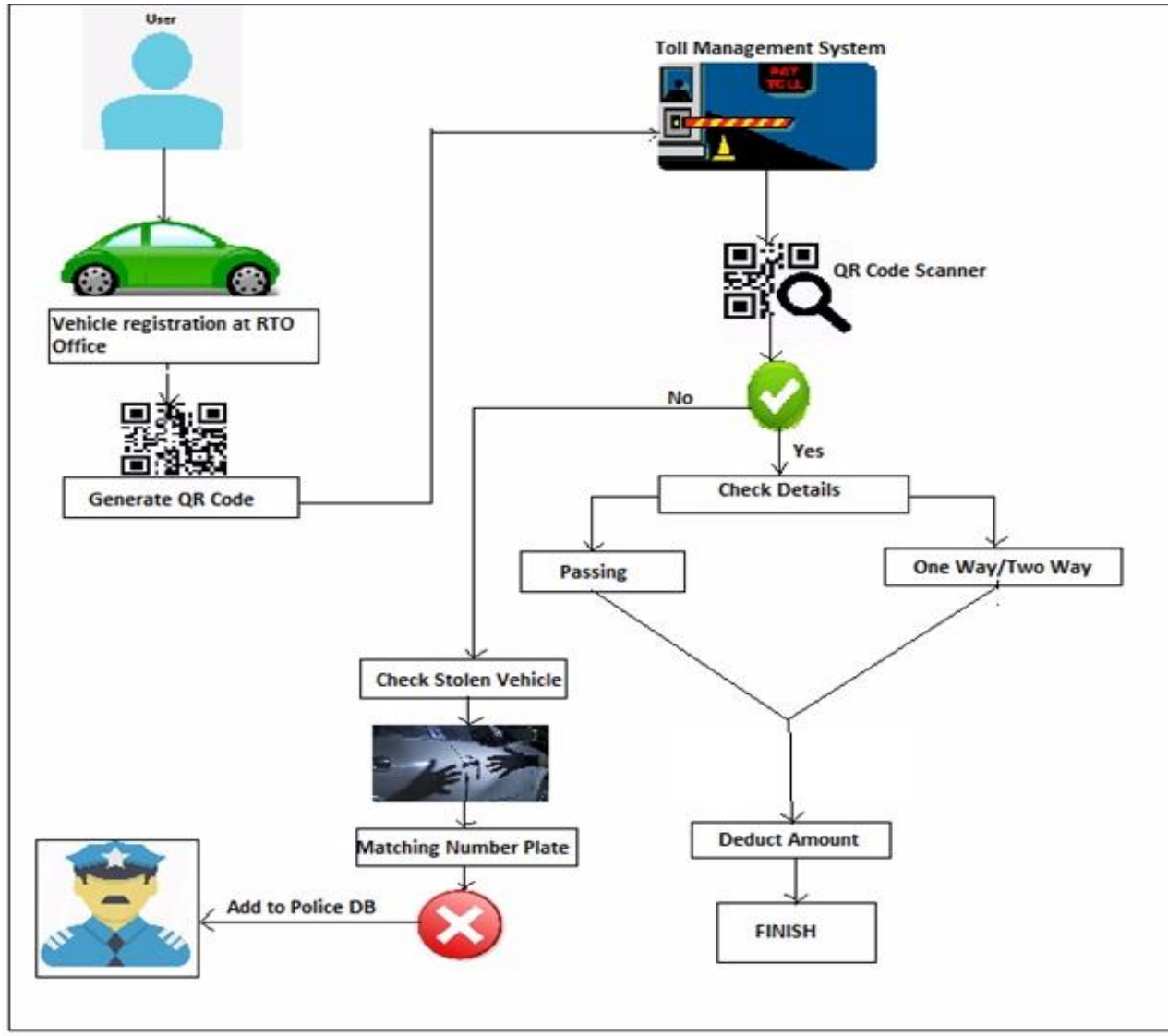

1.

2.

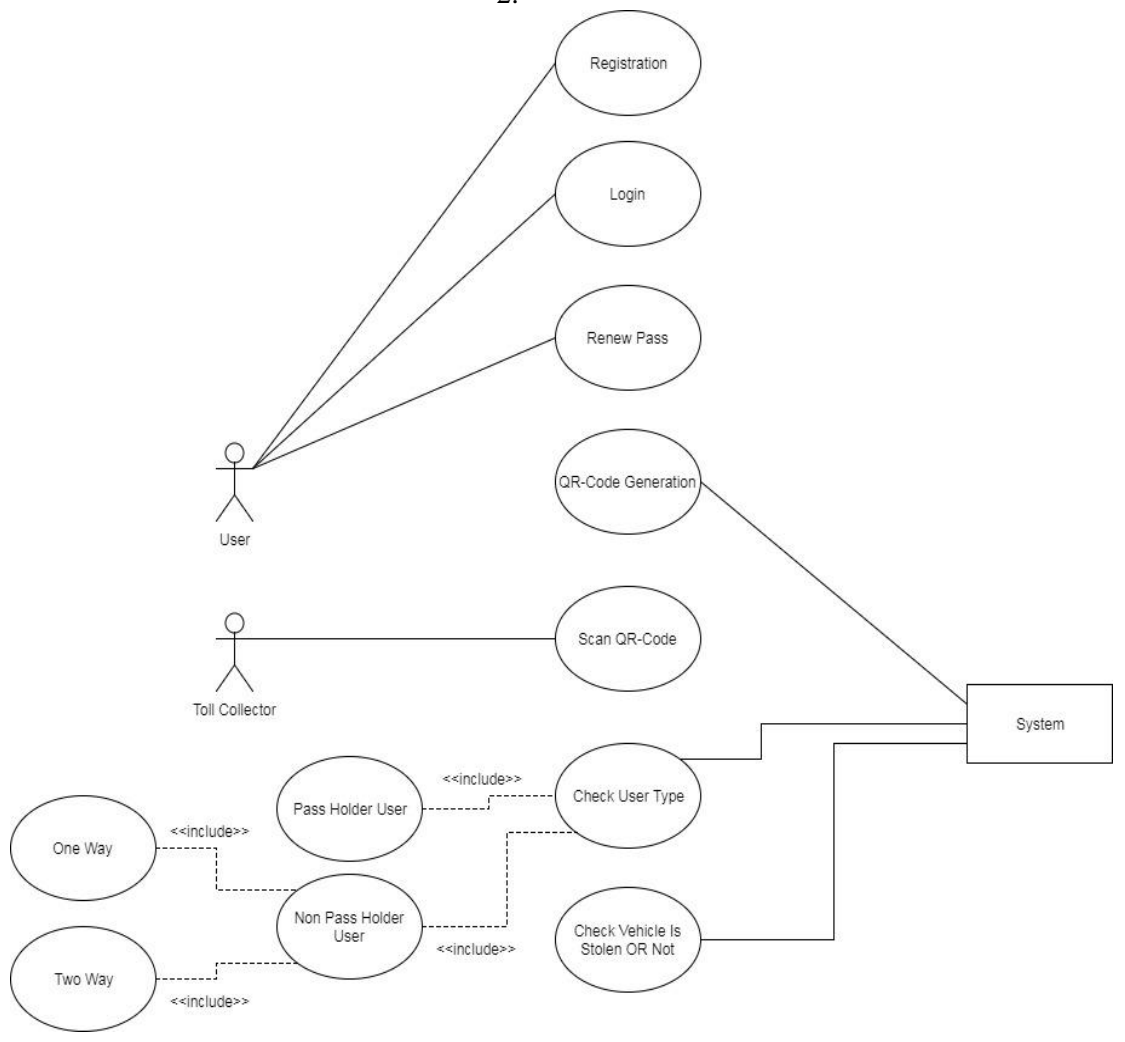


3.

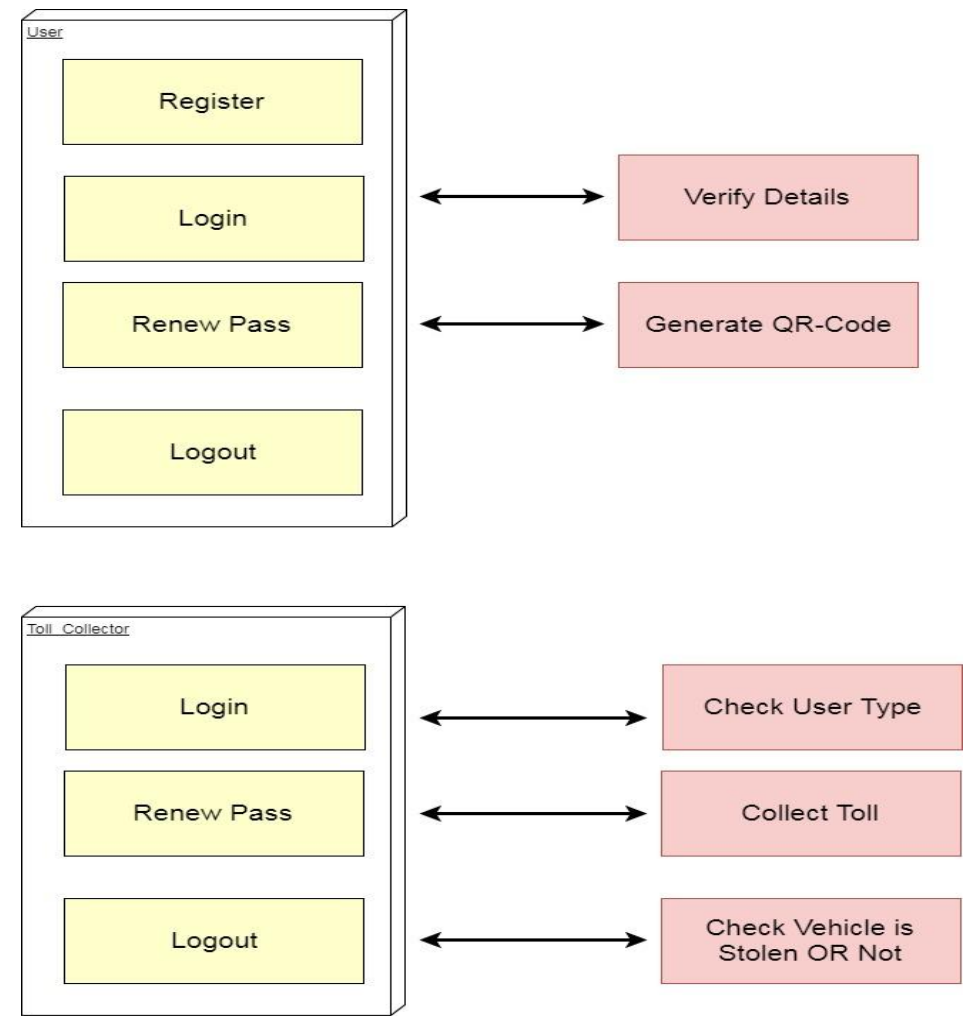

V. SYSTEM REQUIREMENT

Hardware Requirements:

\begin{tabular}{|l|l|}
\hline System & Intel I3Processor. \\
\hline Hard Disk & 40 GB. \\
\hline Monitor & 15 VGA Colour. \\
\hline Mouse & Logitech. \\
\hline Ram & 4 GB \\
\hline
\end{tabular}

Software Requirements:

\begin{tabular}{|l|l|}
\hline Operating system: & Windows 7 and above. \\
\hline Coding Language & JAVA, ANDROID \\
\hline IDE & Android Studio \\
\hline Database & SQLite, MYSQL. \\
\hline
\end{tabular}

\section{CONCLUSION}

QR-Code is effective way to store information also effective way to handle stored data. We propose effective and transparent toll collection system. Toll collector just has to scan QR code; other operations will perform automatically. Automated toll collection system reduces the time required to collect toll. Also propose system is capable of identify

Vehicle is stolen or not. This feature will track stolen vehicle.

\section{REFERENCES}

[1]. The Time's of India paper April 20,2016 "Now Road toll can be paid without stopping at Toll Plazas".

[2]. The Time's of India paper May 28, 2016 "High-Tech number plates for 20 lakh vehicles soon".

[3]. Tom Pettruzzelis,"TELEPHONE PROJECTS FOR THE EVIL GENIUS",BPB PUBLICATIONS

[4]. Klaus Finkenzeller, "RFID Handbook: Radio-Frequency Identification Fundamentals and Applications". John Wiley \&amp; Sons, 2000.

[5]. H. Vogt. Efficient Object identification with passive RFID tags. In F.Mattern and M.

[6]. Naghsinesh, editors, International Conference on Pervasive Computing. Volume 2414 of

[7]. Lecture Notes in Computer Science, pages 98-113, Zurich, August 2002. Springer-Verleg. 